\title{
SOCIAL MEDIA-PRESENCE BASED TRUST FOR ENTERPRISE KNOWLEDGE SHARING: AN EMPIRICAL INVESTIGATION
}

\author{
Eric M. Tamandja, Dakota State University,tamandja@gmail.com \\ Assion Lawson-Body, University of North Dakota, alawsonbody@business.und.edu \\ Lori Willoughby, Minot State University, lori.willoughby@minotstateu.edu \\ Laurence Lawson-Body, University of North Dakota, laurence.lawsonbody@business.und.edu
}

\begin{abstract}
This paper explores social media use as a trust building mechanism for enterprise knowledge sharing. The paper departs from the literature by proposing a social media presence-based trust as an antecedent to knowledge sharing. Our model is built upon social identity and social media theories where individuals in the same network believe that the relationship of online exchange is similar to traditional (face-to-face) interpersonal relationships, and therefore shortens the perceived social distance between them, creating trust. We use PLS-based SEM to empirically test the model. The result shows that connectivity and privilege in a network create social media-based trust. We also test the mediating effect to show that social-media based trust fully mediates the relationship between both the connectivity in the network and the intention to share knowledge and partially mediates the relationship between the privilege in the network and the intention to share knowledge.
\end{abstract}

Keywords: Knowledge Sharing, Trust, Social Media Presence, Connectivity, Privilege, Proximity

\section{INTRODUCTION}

In the era of data, information, and knowledge economy, knowledge is the most valuable resource and is of vital importance for organizations. Knowledge sharing is known to promote development of new technologies and products (Nonaka \& Takeuchi, 1995). Many researchers have suggested that the ability of an organization's members to combine and exchange knowledge determines the rate at which new products and services are introduced (Smith, Collins, \& Clark, 2005). However, sharing knowledge is a challenge in practice.

Trust is a major factor behind people's decision to share or not to share knowledge. When trust exists, individuals are more willing to share knowledge and consequently increase performance. Mayer, Davis, \& Schoorman (1995) defined trust as a willingness to be vulnerable to the actions of another party based on the expectation that the other will perform a particular action important to the trustor, irrespective of the ability to monitor or control that other party.

In today's networked context, trust is valuable as social media is a part of knowledge workers' activities, with engineers and scientists roughly five time more likely to turn to a person for information than to an impersonal source such as databases (Cross, Parker, Prusak, \& Borgatti, 2001). In spite of this, research on trust as social reality is broad. The focus of this research is on social media presence-based trust grounded in social identity and social capital theory. Based on the social identity theory, individuals engage in processes of social comparison to confirm their distinctiveness, value, and self-worth (Hogg \& Terry, 2000), and social media allows such conceptions. Social capital is a term that encompasses the norms and networks facilitating collective actions for mutual benefits (Woolcock, 1998). Trust, defined as willingness to take initiatives (or risk) in a social context based on the assumption that others will respond as expected, is one of many possible representations of social capital (Wasko \& Faraj, 2005).

Many researchers have predicted the influence of trust on knowledge sharing. However, there is surprisingly little empirical evidence of social media presence-based trust on knowledge sharing and how attributes of social media create trust. The goal of this paper is to understand the role of social media attributes on behavioral intention to trust. 
This study contributes to the research on enterprise knowledge sharing by explicitly introducing social media attributes as powerful, separate constructs.

The rest of the paper is organized as follows: the next section presents a review of the literature on organizational knowledge sharing and trust. This section provides an application of social capital and social identity theory to develop hypotheses for examining how social media presence fosters trust and knowledge sharing. The following section presents the research methodology and data analysis using partial least square-based structural equation modelling (PLS-SEM). The final section discusses the results and how the empirical findings contribute to theory development on social media attributes.

\section{LITERATURE REVIEW AND HYPOTHESES}

Knowledge sharing is identified as a major focus in the knowledge management field (Hendriks, 1999) and many tools are used for facilitating knowledge sharing in organizations (Marshall, 1997). The use of social media to facilitate knowledge sharing in an organization is growing (Majchrzak, Faraj, Kane, \& Azad, 2013) and many authors have explored the affordances of visibility of social media use in organizations (Treem \& Leonardi, 2012). Kiron, Palmer, Phillips, \& Kruschwitz (2012) found that $86 \%$ of managers think that social media will be important to their business in 3 years. As of 2012, four out of five companies worldwide were using social technologies at varying stages of maturity (Overby, 2012). According to Kanawattanachai \& Yoo (2002), one of the fundamental factors that is believed to be important in determining the success and failure of teams is trust. Trust refers to the willingness of parties to accept risk and be vulnerable to others (Mayer, Davis, \& Schoorman, 1995). This willingness to accept vulnerability derives from the party's perceptions of the other's trustworthiness. Three factors appear to be most commonly related to the party's perceptions of the other's trustworthiness (Brower, Schoorman, \& Tan, 2000; Mayer, Davis, \& Schoorman, 1995) : perceived ability refers to the trustor's belief that the other party is competent and can accomplish a specific task very well without difficulty, perceived integrity refers to the trustor's belief that the other party has good ethical and moral principles, and perceived benevolence refers to the trustor's belief that the other party cares. All three perceptions of trustworthiness are empirically tested and significantly related to trust.

Levin, Whitener, \& Cross (2006) drew attention to the fact that benevolence-based trust and competence-based trust mediate the flow of knowledge, and competence-based trust is needed by the receiver of tacit knowledge on an individual level. The three dimensions of trust proposed by Levin, Whitener, \& Cross (2006) are more effective within a network where benevolence is proven by a degree centrality of the knowledge worker. Ardichvili, Page, \& Wentling (2003) proposed trust building mechanisms to overcome barriers to knowledge sharing and increase effectiveness of these concepts.

Usoro, Sharratt, Tsui, \& Shekhar (2007) found that there is one more dimension to add to both competence-based trust and benevolence-based trust, which is integrity-based trust. They argued that integrity-based trust is based on the compatibility of the community's cultural values with those of the trusting member, the credibility of the community's reputation, and the consistency of the community member's past behavior, such as the extent to which actions are congruent with words (Usoro, Sharratt, Tsui, \& Shekhar, 2007). This dimension is important to maintain a social network.

Some authors argued that weak ties in social networks provide access to non-redundant information (Granovetter, 1973) and are useful (Szulanski, 1996), while other authors suggested that strong ties lead to greater knowledge exchange (Uzzi, 1997). Wasko \& Faraj (2005) found that people contribute their knowledge when they are structurally embedded in the network. They further found that agent may share regardless of expectations of reciprocity from others or high levels of commitment to the network (Wasko \& Faraj, 2005). We argue that members in the same network, such as social media networks, are more likely to trust each other and share knowledge related to their work.

$\mathrm{H}_{1}$ : Social media presence-based trust influences the intention to share knowledge 
Hogg and Terry (2000) proposed an extension of social identity theory that provides a basis for understanding trust and relationship length. They posited that individuals are motivated to reduce uncertainty and establish their similarities and differences with others to enhance self-esteem and self-identity (Hogg \& Terry, 2000). Further, Wasko and Faraj (2005) found that individuals who are central to the network and connected to a large number of others are more likely to sustain contributions and trust to the collective. Also, a sense of self-identity could directly boost knowledge contribution (Ma \& Agarwal, 2007). According to the theory of recognition heuristics (Goldstein \& Gigerenzer, 1999), people place higher value on objects they recognize than on objects they don't, regardless of their actual values. When everybody knows a member in the network, they usually seek information from him or her regardless of expertise. We argue that members who know many other members are more likely to be trusted.

$\mathrm{H}_{2}$ : Connectivity in the network creates social media presence-based trust

The concept of social presence is derived from social presence theory (Short, Williams, \& Christie, 1976), and it refers to the extent to which a medium is perceived as truly conveying the presence of the communicating participants (Rice, 1993). Social presence, which is akin to the notion of information richness (Daft \& Lengel, 1986), creates a perceptual illusion in which a user perceives distant entities as being close. We use the concept of social presence to capture the extent to which knowledge workers perceive that social networks effectively convey the presence of close friendship. Social presence closely relates to intimacy and psychological closeness (Short, Williams, \& Christie, 1976) and it addresses the social dimension of online exchange relationships. Social presence shortens the perceived social distance between co-workers in the network, making one believe that the online exchange relationship is similar to traditional (face-to-face) interpersonal relationships (Kumar \& Benbasat, 2002). We argue that members that have constant exchange on their social media are more likely to trust each other.

\section{$\mathrm{H}_{3}$ : Proximity in the network creates social media presence-based trust}

Privilege in a network is a concept that refers to the extent to which a member of the network's importance is determined by how essential its neighbors are. That is, individuals in a network might like to account not only for the connectivity or closeness of an individual to many others, but also for its proximity to many other "important" neighbors (Katz \& Shapiro, 1994). In practice, who you know determines how important you are in the network and the weighted sum of not only direct connections are important, but indirect connections are also very important (Bonacich, 1972). We then argue that having friends in common will allow users to trust one another even they are not connected.

$\mathrm{H}_{4}$ : Privilege in the network creates social media presence-based trust

\section{METHODOLOGY}

We use Partial Least Square (PLS)-based Structural Equation Modeling (SEM) for two reasons. First, because the PLS-based SEM methodology is widely used in MIS research (Goodhue, Lewis, \& Thompson, 2006), and second, PLS-based SEM tolerates small sized samples better than regression and covariance-based SEM. However, the sample size must ensure sufficiently stable path coefficient estimates (accuracy) and provide adequate levels of statistical power (Marcoulides \& Saunders, 2006). The above requirements will be fulfilled by running the bootstrapping algorithm for the test of significance and the PLS algorithm for the parameters estimation with 500 iterations.

\section{Subjects}

The sample consisted of 31 senior and midrange managers of a large company in Togo (West Africa). The company is the major energy distributor of the country with 784 million $\mathrm{kWh}$ in 2015 and an $11.52 \%$ growth rate in terms of 
revenue. All 31 respondents returned the survey in a timely manner. The items are translated from the respondents' native language (French) by one of the researchers.

\section{Measurement Development}

We validated the instruments using a quasi-experiment design approach. We developed the measures from the literature and an initial pre-test was run. All attitudinal items were measured on 5 point Likert scales. Intention to share is the variable named according to the theory of planned behavior (TPB), which asserts that intention is assumed to be the immediate antecedent of behavior (Ajzen, 1985). Intention to share is measured with five items adapted from Davis Jr (1986). Social media presence-based trust is also measured with five items from the Krishna \& Shrader (1999) scale, used by the World Bank and academic scholars. We replaced the words "trust in community" in the scale with "In my social network." We used this instrument because it had been validated in the context of globally diverse respondents in multiple countries and cultures (Krishna \& Shrader, 1999). Connectivity in the network is measured with two items, proximity in the network is measured with two items, and privilege in the network is measured with two items.

The questionnaire contains multiple measurement items relating to each of the constructs defined in the research model (Figure 1). We performed a pre-test for comprehensiveness and clearness using faculty and graduate students trained in questionnaire design (Dillman, 1978).

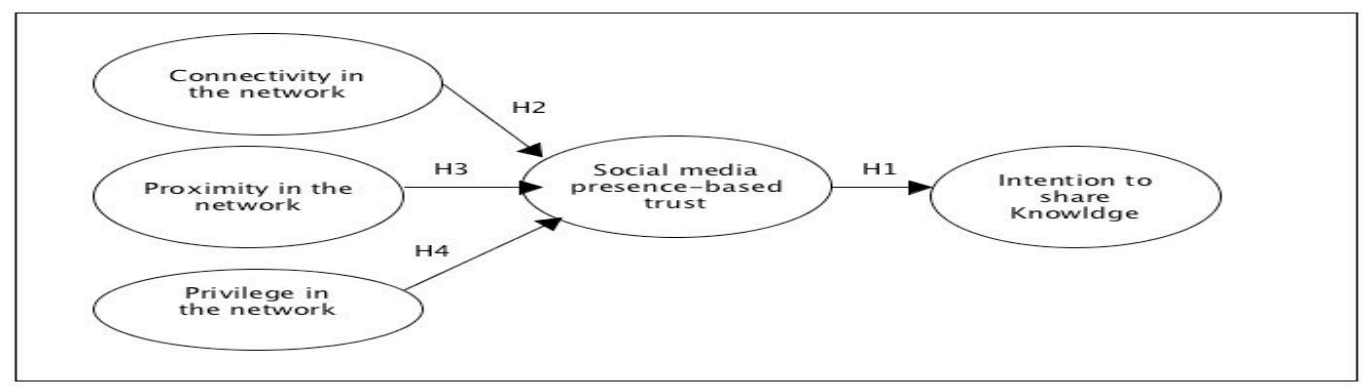

Figure 1. Social Media Presence Based-Trust for Enterprise Knowledge Sharing Model

\section{Structural Model Assessment}

Construct validity is defined as the extent to which an instrument effectively measures the theoretical construct when operationalization occurs and how well the metrics show stability across methodologies (Straub, 1989). There are two types of construct validity: translation validity (face validity, content validity), and criterion-related validity (predictive validity, concurrent validity, convergent validity, and discriminant validity).

Face validity: an expert panel of 10 graduate students and faculty that are aware of knowledge sharing literature and trained in survey design have examined the items. Content validity: the representativeness and comprehensiveness of the items used to create a scale (Straub, 1989). Content validity is also assessed by the panel of 10 graduate students and faculty that are aware of knowledge sharing literature and trained in survey design. Using PLS-based SEM, we focus on factorial validity in terms of convergent and discriminant validity.

Table 1. Constructs Description

\begin{tabular}{|l|l|}
\hline $\begin{array}{l}\text { Modelling } \\
\text { Constructs }\end{array}$ & Description \\
\hline $\begin{array}{l}\text { Intention to } \\
\text { share }\end{array}$ & $\begin{array}{l}\text { ISH is the degree to which one } \\
\text { kelieves that one will engage in a }\end{array}$ \\
(ISH) & $\begin{array}{l}\text { knowledge } \\
\text { sharing act after a positive feeling } \\
\text { about it (Ajzen \& Fishbein, 1980), }\end{array}$ \\
\hline
\end{tabular}




\begin{tabular}{|l|l|}
\hline & (Constant, Kiesler, \& Sproull, 1994). \\
\hline $\begin{array}{l}\text { Social } \\
\text { media } \\
\text { presence } \\
\text { based-trust } \\
\text { (SMP) }\end{array}$ & $\begin{array}{l}\text { SMP is a combination of coworkers' } \\
\text { perceptions of the other's } \\
\text { trustworthiness by being in the same } \\
\text { network (Krishna \& Shrader, 1999). }\end{array}$ \\
\hline $\begin{array}{l}\text { Proximity in } \\
\text { the network } \\
\text { (PXT) }\end{array}$ & $\begin{array}{l}\text { PXT is the extent to which a } \\
\text { knowledge worker perceives the } \\
\text { socio-network to effectively convey } \\
\text { the presence of close friendship } \\
\text { (Borgatti, 2005). }\end{array}$ \\
\hline $\begin{array}{l}\text { Connectivity } \\
\text { in the } \\
\text { network } \\
\text { (CNE) }\end{array}$ & $\begin{array}{l}\text { CNE refers to the extent to which } \\
\text { members of a social network have a } \\
\text { relatively high proportion of direct } \\
\text { ties to other members (Wasko \& } \\
\text { Faraj, 2005). }\end{array}$ \\
\hline $\begin{array}{l}\text { Privilege in } \\
\text { the network } \\
\text { (PRV) }\end{array}$ & $\begin{array}{l}\text { PRV is the extent to which a } \\
\text { member of the network's importance } \\
\text { is determined by how important its } \\
\text { neighbors are. (Bonacich, 1972). }\end{array}$ \\
\hline
\end{tabular}

Table 2 shows the t-statistics and provides information about whether the model hypotheses are supported. It is expected that convergent validity be shown when the t-values of the outer model loadings are above 1.96 for the two-tailed test and 0.98 for the one tailed test. The results indicate that all paths are statistically significant using the one tailed test.

Table 2. Paths and T-statistics

\begin{tabular}{|l|l|}
\hline Paths & T-statistics \\
\hline CNE -> SMP & 25.97 \\
PRV -> SMP & 1.81 \\
PXT -> SMP & 2.04 \\
SMP -> ISH & 1.22 \\
\hline
\end{tabular}

Convergent validity is the extent to which each measurement item loads with a significant t-value on its latent construct (Table 3).

Table 3. Factor Loadings

\begin{tabular}{|c|c|c|c|c|c|}
\hline Variables & CNE & ISH & PRV & PXT & SMP \\
\hline CNE 1 & 0.79 & & & & \\
\hline CNE 2 & 0.87 & & & & \\
\hline ISH 1 & & 0.89 & & & \\
\hline ISH 2 & & 0.80 & & & \\
\hline ISH 3 & & 0.58 & & & \\
\hline ISH 4 & & 0.63 & & & \\
\hline ISH 5 & & 0.92 & & & \\
\hline PRV 1 & & & 0.80 & & \\
\hline PRV 2 & & & 0.95 & & \\
\hline PXT 1 & & & & 0.96 & \\
\hline PXT 2 & & & & 0.97 & \\
\hline SMP 1 & & & & & 0.87 \\
\hline SMP 2 & & & & & 0.88 \\
\hline SMP 3 & & & & & 0.92 \\
\hline
\end{tabular}




\begin{tabular}{|c|l|l|l|l|c|}
\hline SMP 4 & & & & & -0.50 \\
\hline SMP 5 & & & & & 0.59 \\
\hline
\end{tabular}

Table 3 shows factor loadings and each item is loaded at $>.70$ on the respective latent variable except SMP 4, SMP 5 , ISH 3, and ISH 4, which are candidates for deletion. However, no action is needed at this point.

Discriminant validity indicates the extent to which a construct is different from the other constructs. The measures of the construct should be distinct and the indicators should load on the appropriate construct and should share more variance with its measure than with other constructs in the model (Barclay, Higgins, \& Thompson, 1995). An appropriate average variance extracted (AVE) requires that the square root of each latent construct's AVE is much larger than the correlation of that specific construct with any of the other constructs in the model. To demonstrate discriminant and convergent validity, we inspected the loading and cross loading of each indicator. Each construct should load higher on the construct than on any other factor (Chin, 2000). The inspection of loadings (Table 3) confirms that the observed indicators demonstrate adequate discriminant and convergent validity. Table 4 shows a correlation matrix where the diagonal is replaced by the squared root of each latent construct's AVE for discriminant validity.

Table 4. Discriminant Validity Metrics

\begin{tabular}{|c|c|c|c|c|c|}
\hline & CNE & ISH & PRV & PXT & SMP \\
\hline CNE & 0.83 & & & & \\
\hline ISH & 0.21 & 0.78 & & & \\
\hline PRV & 0.64 & 0.01 & 0.88 & & \\
\hline PXT & 0.77 & 0.17 & 0.66 & 0.96 & \\
\hline SMP & 0.66 & 0.22 & 0.50 & 0.44 & 0.77 \\
\hline
\end{tabular}

Internal validity deals more with the relationship among constructs in the conceptual model. The question to ask is whether the relationship is causal. In a cause-effect study, one must establish and substantiate evidence causal relationships. Three criteria must be met to do so: temporal precedence, co-variation of the cause and the effect, and no plausible alternative explanation. The designed model (Figure 1) demonstrated temporal precedence where social media attributes create trust, which is an antecedent for knowledge sharing.

Reliability is the degree to which the metrics chosen to measure a certain construct are consistent. Reliability is assessed by Cronbach's alpha (greater than 0.7) for internal consistency, the AVE greater than 0.5, and the composite reliability greater than 0.7 (Table 5).

Table 5. Reliability Statistics

\begin{tabular}{|c|c|c|c|}
\hline $\begin{array}{c}\text { Latent } \\
\text { Variables }\end{array}$ & $\begin{array}{c}\text { Cronbach's } \\
\text { alpha } \\
\mathbf{> 0 . 7}\end{array}$ & $\begin{array}{c}\text { Average } \\
\text { Variance } \\
\text { Extracted } \\
\text { (AVE) } \\
>\mathbf{0 . 5}\end{array}$ & $\begin{array}{c}\text { Composite } \\
\text { reliability } \\
\text { (CR) }>\mathbf{0 . 7}\end{array}$ \\
\hline CNE & 0.5518 & 0.6888 & 0.8154 \\
\hline ISH & 0.8452 & 0.6008 & 0.8794 \\
\hline PRV & 0.7341 & 0.7742 & 0.8719 \\
\hline PXT & 0.9245 & 0.9298 & 0.9636 \\
\hline SMP & 0.6019 & 0.5907 & 0.7871 \\
\hline
\end{tabular}

The reliability assessment indicates that Cronbach's alpha for connectivity construct and social media presence is below the threshold. However, the composite reliability is above the threshold. Therefore, our model exhibits the sound reliability and validity necessary for further testing of our research hypotheses. 


\section{RESULTS AND DISCUSSION}

\section{Hypothesis Test Results}

Hypothesis test results are presented in Table 6. Using the PLS algorithm, the results indicate that social media presence based-trust influence behavioral intention to share knowledge ( $\mathrm{SMP}->\mathrm{ISH}=0.22$ ), which is consistent with Wasko \& Faraj's (2005) findings. The more social media artifact available, the better knowledge is shared among trusted members. The study supports the hypothesis that connectivity in a network creates social media based-trust $(\mathrm{CNE}->\mathrm{SMP}=0.71)$. This is also consistent with the social media attributes literature; the higher degree centrality is a node the more trusted that node is, and its degree distribution follows a power law (Barabási \& Bonabeau, 2003). The hypothesis that proximity in the network creates social media presence based-trust is not supported (PXT$>\mathrm{SMP}=-0.24)$. This can be explained by the fact that being a close friend does not mean that he or she is trustworthy. This is also consistent with the study of the strength of weak ties we can trust (Levin \& Cross, 2004). The hypothesis that privilege in a network creates social media presence based-trust is supported (PRV$>\mathrm{SMP}=0.20$ ). The implication for this hypothesis is that small word law governs members of a network. Every member wants to maximize his utility with members that are not directly connected to him or her.

Table 6. Hypothesis Test Eesults

\begin{tabular}{|l|l|l|}
\hline \multicolumn{1}{|c|}{ Hypotheses } & $\begin{array}{l}\text { Parameters } \\
\text { Estimated }\end{array}$ & Supported? \\
\hline $\begin{array}{l}\text { H1: Social media } \\
\text { presence based- } \\
\text { trust influences } \\
\text { intention to share } \\
\text { knowledge }\end{array}$ & 0.224 & YES \\
\hline $\begin{array}{l}\text { H2: Connectivity } \\
\text { in the network } \\
\text { creates social } \\
\text { media presence } \\
\text { based-trust }\end{array}$ & 0.714 & YES \\
\hline $\begin{array}{l}\text { H3: Proximity in } \\
\text { the network } \\
\text { creates social } \\
\text { media presence } \\
\text { based trust }\end{array}$ & -0.242 & NO \\
\hline $\begin{array}{l}\text { H4: Privilege in } \\
\text { the network } \\
\text { creates social } \\
\text { media presence } \\
\text { based- trust }\end{array}$ & 0.206 & YES \\
\hline
\end{tabular}

\section{Testing For Mediating Effect}

To demonstrate that social media presence based-trust mediates the link between social media attributes and knowledge sharing, four conditions must hold (Baron \& Kenny, 1986). First, social media presence based-trust alone must have a positive impact on knowledge sharing $(\mathrm{SMP}->\mathrm{ISH}=0.22)$.

Second, social media attributes must have a positive significant impact on social media presence based-trust (CNE$>\mathrm{SMP}=0.71),(\mathrm{PRV}->\mathrm{SMP}=0.20)$. Third, when a direct path is created between social media attributes and intention to share knowledge, this path must be non-significant to conclude full mediation. Otherwise, if all paths are still significant after creating a direct path, then a partial mediation is concluded (Burton-Jones \& Hubona, 2006). 
To test the third condition, we created a direct path between connectivity in the network and intention to share knowledge (Figure 2). The result (CNE->ISH) shows that the coefficient is statically non-significant, thus SMP fully mediates the relationship.

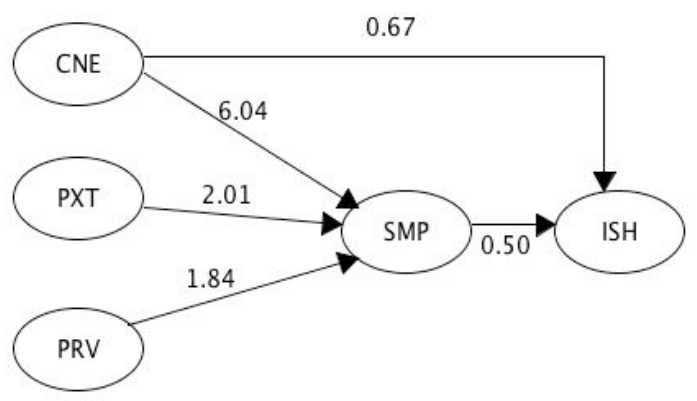

Figure 2. Mediating Effect Eesults 1

We then created a direct path between privilege in the network and the intention to share knowledge (Figure 3). The result (PRV-> ISH) suggests that SMP partially mediates the relationship between the two latent constructs. We did not test for proximity because the relationship did not meet the second condition.

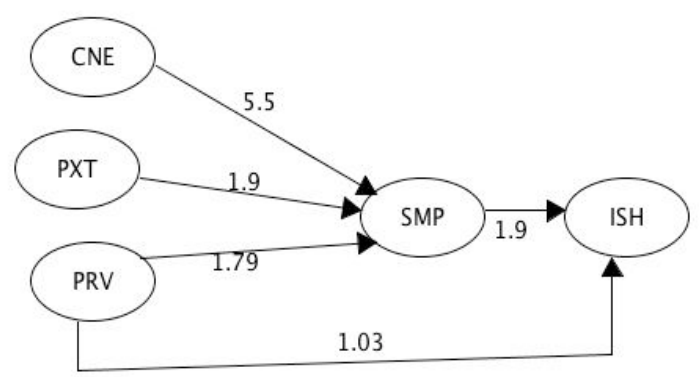

Figure 3. Mediating Effect Results 2

\section{IMPLICATIONS AND FUTURE WORKS}

Social media-based trust is as important as face-to-face based trust for knowledge sharing. This study advances the understanding of each social media attributes' weight on knowledge sharing as a good starting point for the design of social media factors that positively influence knowledge sharing. For researchers, a new concept related to trust emerges and needs more attention and investigation, namely elaboration on social media-based trust. An exploratory factor analysis with the same or a larger data set is needed for better capturing significant factors involved in social media-based trust along with building a good theory behind the concept. For example, one can investigate the nature of the relationship in the network using the content of the message exchanged instead of the structure of the network. As with any empirical study, this study is subject to limitations which have to do with methodology. The survey was conducted in only one organization which raises the problem of generalization across organizations. The sample size is adequate with the PLS techniques, but to avoid many iterations, a reasonably larger sample size is 
always better. The author hopes that future research tests the moderating effect between social media attributes of different levels and social media presence-based trust constructs.

\section{CONCLUSION}

The objective of the study was to formulate and test empirically a model of how social media attributes create social media presence-based trust and how it influences knowledge sharing. This paper's goal was to develop the concept of social media-based trust with regard to social media attributes. Our research model successfully integrates social media attributes, namely: connectivity, proximity, and privilege as positively influencing trust in a network setting. The results support the proposed model, except for the proximity attributes as creating trust in a network.

\section{ACKNOWLEDGEMENTS}

We would like to thank Dr Jun Liu, Assistant Professor at the College of Business and Information Systems, Dakota State University, for his helpful comments for the model design improvement.

\section{REFERENCES}

Ajzen, I. (1985). From intentions to actions: A theory of planned behavior. In J. Kuhl \& J. Beckmann, (Eds.), Action control: From cognition to behaviour (pp. 11-39). Berlin: Springer-Verlag.

Ajzen, I., \& Fishbein, M. (1980). Understanding attitudes and predicting social behaviour. Englewood Cliffs, NJ: Prentice-Hall.

Ardichvili, A., Page, V., \& Wentling, T. (2003). Motivation and barriers to participation in virtual knowledgesharing communities of practice. Journal of knowledge management, 7(1), 64-77.

Barabási, A.-L., \& Bonabeau, E. (2003). Scale-free networks. Scientific American, 288(5), 50-59.

Barclay, D., Higgins, C., \& Thompson, R. (1995). The partial least squares (PLS) approach to causal modeling: Personal computer adoption and use as an illustration. Technology studies, 2(2), 285-309.

Baron, R. M., \& Kenny, D. A. (1986). The moderator-mediator variable distinction in social psychological research: Conceptual, strategic, and statistical considerations. Journal of Personality and Social Psychology, 51(6), 1173.

Bonacich, P. (1972). Factoring and weighting approaches to status scores and clique identification. Journal of Mathematical Sociology, 2(1), 113-120.

Borgatti, S. P. (2005). Centrality and network flow. Social networks, 27(1), 55-71.

Brower, H. H., Schoorman, F. D., \& Tan, H. H. (2000). A model of relational leadership: The integration of trust and leader-member exchange. The Leadership Quarterly, 11(2), 227-250.

Burton-Jones, A., \& Hubona, G. S. (2006). The mediation of external variables in the technology acceptance model. Information \& Management, 43(6), 706-717. 
Chin, W. W. (2000). Partial least squares for researchers: An overview and presentation of recent advances using the PLS approach. Retrieved 24 April, 2007. di sc-nt. cba. uh. edu/chin/icis2000plstalk. pdf.

Constant, D., Kiesler, S., \& Sproull, L. (1994). What's mine is ours, or is it? A study of attitudes about information sharing. Information systems research, 5(4), 400-421.

Cross, R., Parker, A., Prusak, L., \& Borgatti, S. P. (2001). Knowing what we know:: Supporting knowledge creation and sharing in social networks. Organizational dynamics, 30(2), 100-120.

Daft, R. L., \& Lengel, R. H. (1986). Organizational information requirements, media richness and structural design. Management science, 32(5), 554-571.

Davis Jr, F. D. (1986). A technology acceptance model for empirically testing new end-user information systems: Theory and results. Massachusetts Institute of Technology.

Dillman, D. A. (1978). Mail and telephone surveys (Vol. 3): Wiley Interscience.

Goldstein, D. G., \& Gigerenzer, G. (1999). The recognition heuristic: How ignorance makes us smart.

Goodhue, D., Lewis, W., \& Thompson, R. (2006). PLS, small sample size, and statistical power in MIS research. Paper presented at the System Sciences, 2006. HICSS'06. Proceedings of the 39th Annual Hawaii International Conference on.

Granovetter, M. S. (1973). The strength of weak ties. American journal of sociology, 1360-1380.

Hendriks, P. (1999). Why share knowledge? The influence of ICT on the motivation for knowledge sharing. Knowledge and process management, 6(2), 91-100.

Hogg, M. A., \& Terry, D. I. (2000). Social identity and self-categorization processes in organizational contexts. Academy of management review, 25(1), 121-140.

Kanawattanachai, P., \& Yoo, Y. (2002). Dynamic nature of trust in virtual teams. The Journal of Strategic Information Systems, 11(3), 187-213.

Katz, M. L., \& Shapiro, C. (1994). Systems competition and network effects. The Journal of Economic Perspectives, 93-115.

Kiron, D., Palmer, D., Phillips, A. N., \& Kruschwitz, N. (2012). Social business: What are companies really doing. MIT Sloan Management Review, 53(4), 1-32.

Krishna, A., \& Shrader, E. (1999). Social capital assessment tool. Paper presented at the conference on social capital and poverty reduction, World Bank, Washington, DC.

Kumar, N., \& Benbasat, I. (2002). Para-social presence and communication capabilities of a web site: a theoretical perspective. E-service Journal, 1(3), 5-24.

Levin, D. Z., \& Cross, R. (2004). The strength of weak ties you can trust: The mediating role of trust in effective knowledge transfer. Management science, 50(11), 1477-1490.

Levin, D. Z., Whitener, E. M., \& Cross, R. (2006). Perceived trustworthiness of knowledge sources: the moderating impact of relationship length. Journal of Applied Psychology, 91(5), 1163. 
Ma, M., \& Agarwal, R. (2007). Through a glass darkly: Information technology design, identity verification, and knowledge contribution in online communities. Information systems research, 18(1), 42-67.

Majchrzak, A., Faraj, S., Kane, G. C., \& Azad, B. (2013). The contradictory influence of social media affordances on online communal knowledge sharing. Journal of Computer-Mediated Communication, 19(1), 38-55.

Marcoulides, G. A., \& Saunders, C. (2006). PLS: A silver bullet? Management Information Systems Quarterly, $30(2), 1$.

Marshall, L. (1997). Facilitating knowledge management and knowledge sharing: new opportunities for information professionals. Online, 21(5), 92-98.

Mayer, R. C., Davis, J. H., \& Schoorman, F. D. (1995). An integrative model of organizational trust. Academy of management review, 20(3), 709-734.

Nonaka, I., \& Takeuchi, H. (1995). The knowledge-creating company: How Japanese companies create the dynamics of innovation: Oxford university press.

Overby, E. (2012). Migrating processes from physical to virtual environments: Process virtualization theory Information Systems Theory (pp. 107-124): Springer.

Rice, R. E. (1993). Media appropriateness. Human communication research, 19(4), 451-484.

Short, J., Williams, E., \& Christie, B. (1976). The social psychology of telecommunications.

Smith, K. G., Collins, C. J., \& Clark, K. D. (2005). Existing knowledge, knowledge creation capability, and the rate of new product introduction in high-technology firms. Academy of Management Journal, 48(2), 346-357.

Straub, D. W. (1989). Validating instruments in MIS research. MIS quarterly, 147-169.

Szulanski, G. (1996). Exploring internal stickiness: Impediments to the transfer of best practice within the firm. Strategic Management Journal, 17(S2), 27-43.

Treem, J. W., \& Leonardi, P. M. (2012). Social media use in organizations: Exploring the affordances of visibility, editability, persistence, and association. Communication yearbook, 36, 143-189.

Usoro, A., Sharratt, M. W., Tsui, E., \& Shekhar, S. (2007). Trust as an antecedent to knowledge sharing in virtual communities of practice. Knowledge Management Research \& Practice, 5(3), 199-212.

Uzzi, B. (1997). Social structure and competition in interfirm networks: The paradox of embeddedness. Administrative science quarterly, 35-67.

Wasko, M. M., \& Faraj, S. (2005). Why should I share? Examining social capital and knowledge contribution in electronic networks of practice. MIS quarterly, 35-57.

Woolcock, M. (1998). Social capital and economic development: Toward a theoretical synthesis and policy framework. Theory and society, 27(2), 151-208. 


\section{Issues in Information Systems}

Volume 17, Issue II, pp. 44-55, 2016

\section{APPENDIX}

\section{Questionnaire [Five-point Likert type scale]}

Please answer each of the following questions by circling the term that best describes your opinion. Some of the questions may appear to be similar, but they do address somewhat different issues. Please read each question carefully.

\begin{tabular}{|l|l|}
\hline \multicolumn{1}{|c|}{ Variable Name } & \multicolumn{1}{c|}{ Intention to Share Knowledge: } \\
\hline $\mathrm{ISH}_{1}$ & I will help co-workers solve problems in regular bases in the future \\
\hline $\mathrm{ISH}_{2}$ & I will strongly recommend others co-workers to help solve problems \\
\hline $\mathrm{ISH}_{3}$ & I will be happy to help co-worker \\
\hline $\mathrm{ISH}_{4}$ & Helping motivates me to learn from others co-workers \\
\hline $\mathrm{ISH}_{5}$ & I will frequently help solve co-worker's problems in the future \\
\hline
\end{tabular}

\begin{tabular}{|l|l|}
\hline Variable Name & Social media presence based-trust \\
\hline $\mathrm{SMP}_{1}$ & I feel that most people on my socio-network are basically honest and can be trusted \\
\hline $\mathrm{SMP}_{2}$ & I feel that co-workers in my socio-network are always interested on everybody welfare \\
\hline $\mathrm{SMP}_{3}$ & I feel that co-workers of my socio-network are always trustworthy \\
\hline $\mathrm{SMP}_{4}$ & $\begin{array}{l}\text { I feel that in my socio-network, one has to be alert or someone is likely to take } \\
\text { advantage of you (Reverse) }\end{array}$ \\
\hline $\mathrm{SMP}_{5}$ & I feel that my socio-network fiends are willing to help if you need it \\
\hline
\end{tabular}

\begin{tabular}{|l|l|}
\hline Variable Name & Connectivity in the network \\
\hline $\mathrm{CNE}_{1}$ & I have many friends in my network \\
\hline $\mathrm{CNE}_{2}$ & I can trust my friends \\
\hline
\end{tabular}

\begin{tabular}{|l|l|}
\hline Variable Name & Proximity in the network \\
\hline $\mathrm{PXT}_{1}$ & I have close friends in my network \\
\hline $\mathrm{PXT}_{2}$ & I can trust my close friends \\
\hline
\end{tabular}

\begin{tabular}{|l|l|}
\hline Variable Name & Privilege in the network \\
\hline $\mathrm{PRV}_{1}$ & I have important friends in my network \\
\hline $\mathrm{PRV} V_{2}$ & I can trust my important friends \\
\hline
\end{tabular}

